\title{
Computation of the implied discount rate and volatility for an overdefined system using stochastic optimization*
}

\author{
Lin-Ye HiN $^{\dagger}$ AND NiKolai Dokuchaev ${ }^{\ddagger}$
}

Submitted: 20th March 2014. Accepted: 23rd January 2015.

\begin{abstract}
This paper studies estimation of the implied volatility and the impact of the choice of the corresponding risk-free rate proxy. We suggest to analyze the implied volatility and the riskfree rate proxy inferred in conjunction with the observed option prices. We formulate and solve an overdefined system of nonlinear equations for the Black-Scholes model using options data. More precisely, we seek an optimal approximate solution via differential evolution, a stochastic optimization technique. Some experiments with historical prices reveal a higher inferred risk-free rate than commonly used proxies. This leads to narrower volatility spread, or smaller difference between implied and realized volatilities.
\end{abstract}

Keywords: Implied volatility, optimization, risk-free rate.

JEL codes: C14, C51, C58, C61, G13.

*This work was supported by ARC grant of Australia DP120100928. We thank participants at the IMS-FPS 2014 Workshop at University Technology of Sydney, Australia, and the 6th Australasian Actuarial Education and Research Symposium. We acknowledge provision of ICTsupport and computing resources by Curtin IT Services. Curtin Information Technology Services (CITS) provides Information and Communication Technology systems and services in support of Curtin's teaching, learning, research and administrative activities. We acknowledge use of computing resources from the NeCTAR Research Cloud. NeCTAR is an Australian Government project conducted as part of the Super Science initiative and financed by the Education Investment Fund.

${ }^{\dagger}$ Department of Mathematics and Statistics, Curtin University, GPO Box U1987, Perth, 6845 Western Australia.

*Department of Mathematics and Statistics, Curtin University, GPO Box U1987, Perth, 6845 Western Australia.

This is a pre-copy-editing, author-produced PDF of an accepted for publication in IMA Journal of Management Mathematics following peer review. 


\section{Introduction}

This paper readdresses the estimation of implied volatilities from historical option prices. It is an area of active research and has many practical applications. In particular, it appears that the implied volatility is a better predictor of the future realized volatility of the underlying asset for the remaining lifespan of the option contract than its historical volatility. This applies to both the Black-Scholes (Black and Scholes, 1973) model-based implied volatility, and the model-free implied volatility (Britten-Jones and Neuberger, 2000). Some results for the Black-Scholes model implied volatility and forecasting of the S\&P100 index realized volatility can be found in, e.g., Canina and Figlewski (1993), Corrado and Miller (2005), and Christoffersen et al. (2006). Some results for the model-free implied volatility and forecasting of the S\&P500 index realized volatility can be found in, e.g., Jiang and Tian (2005), and Carr and Wu (2009).

Throughout this compendium of literature, there is a noticeable difference between the implied and realized volatilities. Bakshi and Madan (2006) proposed the notion of volatility spread to quantify this difference. It is more pronounced when the index return distribution is more negatively skewed and leptokurtic in the presence of investor risk aversion. The historical volatilities are usually estimated by the squared-root of the sum of squared log return (see Aït-Sahalia et al., 2003; Bollerslev et al., 2011, among others), while the implied volatilities are estimated from option prices. The calculation of both model-based and model-free implied volatilities requires making assumption on the risk-free rate. Given an option price, different choices of risk-free rate proxy maps it to different implied volatilities, leading to different magnitudes of volatility spread for a given estimate of the realized volatility. To infer the market participants' aggregate expectation of the underlying asset volatility for the remaining lifespan of the option, we have to choose a risk-free rate proxy that matches the market participants' aggregate choice of risk-free rate proxy.

The importance of the choice of risk-free rate proxy, or discount rate, in contingent claim valuation has been emphasized in earlier literature such as Leibowitz et al. (1989) and Adams and Booth (1995). Among more recent work, Palandri (2014) found that risk-free rate has relevant predictive 
information with respect to the conditional variance of individual stock return, and that interest rate changes have different effects for different assets.

Market participants choose risk-free rate proxy that reflect their credit and liquidity risk. In a recent report, the Bank of International Settlement (2013) acknowledge the need for choosing different reference rates as risk-free rate proxy under different situations and the need to seek greater diversity in reference interest rates that better match the individual needs of the market participants. In practice, a combination of reference rates that reflect different levels of risk premia may be used to construct the discount rate term structure appropriate for the context of use.

The current work contributes to the literature by proposing a strategy to simultaneously extract the information on the market participants' choice of risk-free rates proxy and the expectation of the cumulative future volatility of the underlying asset from the same set of option prices. This set of inferred discount rates can be regarded as the implied discount rate with respect to this set of option prices under the risk neutral measure. They can be used in various econometric applications, such as recovering the market participants' aggregate expectation of future realized volatility of the underlying asset.

Currently there is a rich body of literature offering explanations for the presence of volatility spread, including investor risk-aversion (Bakshi and Madan, 2006), and the estimation precision of implied and realized volatilities (see, e.g. Aït-Sahalia et al., 2003; Bollerslev et al., 2011; Jiang and Tian, 2005). We use historical S\&P500 index options data to demonstrate that the implied discount rate may not exactly match the commonly used risk-free rate proxy, leading to implied volatility calculation uncertainty. We suggest this may add to the list of reasons that account for the volatility spread.

We propose to calculate, from a set of option prices, the implied discount rates and implied volatilities as the solutions of a system of nonlinear equations constructed by mapping the option prices to their corresponding implied discount rates and implied volatilities. This approach to infer the discount rate via a system of two equations of this kind was introduced in Dokuchaev (2006). A 
related model was suggested earlier in Butler and Schachter (1996) for different pairs of implied parameters; more precisely, Butler and Schachter (1996) considered the pair of implied stock price and the risk free rates for the calculation of the implied volatility distributions for the case of the unbiased estimate of the option price for random volatility; in this paper, some references can be found for other choices of implied parameters.

We use prices of the same set of options observed at two instances within a reasonably short time interval to construct the system of nonlinear equations, assuming that the implied discount rate and implied volatility for each option contract considered remain the same within this time interval. This leads to an overdefined system of nonlinear equations. We cast the numerical solution for these unknown parameters from this system of equations as an optimization problem. This problem appears to be non-convex. For the numerical solution in search of the global minimum, we use a multi-point stochastic-based direct-search optimization technique known as the ZhangSanderson's algorithm (Zhang and Sanderson, 2009).

We recognize the concern raised in extant literature that gathering data from different dates opens the door to potential nonstationarity and regime shift issues, and potential fluctuation of the related parameters across this time interval (e.g., Aït-Sahalia and Lo, 1998; Aït-Sahalia and Duarte, 2003). This is certainly an issue when day-close data spanning months or years are considered. We emphasize that the proposed algorithm is designed to aggregate data observed within a short enough time interval only; it appears that the data aggregated from two consecutive day-close option prices is sufficient for our purpose, as illustrated using synthetic and empirical data.

The rest of the paper is organized as follows. Section 2 reviews the Black-Scholes option pricing model and defines the notion of implied volatility and implied discount rate in the extended-BlackScholes model. Section 3 describes the proposed algorithm for estimating implied volatilities and implied discount rates jointly from a set of option prices and reports its numerical performance on the synthetic test data. Using historical prices for the European vanilla call option on S\&P500 index, we illustrate the impact of risk-free rate proxy on the calculation of implied volatility and volatility spread. Section 4 discusses related issues. 


\section{Black-Scholes model and implied parameters}

The Black-Scholes option pricing formula (Black and Scholes, 1973) allows calculation of the option prices for the market model consisting of a risk free bond or bank account with the price $B(t), t \geq 0$, and a risky stock with price $S(t), t \geq 0$, where the prices of the stocks evolve as

$$
d S(t)=S(t)(a(t) d t+\delta(t) d W(t)), \quad t>0 .
$$

Here $W(t)$ is a Wiener process, $a(t)$ is an appreciation rate, and $\delta(t)$ is a random volatility coefficient. The initial price $S(0)>0$ is a given deterministic constant. The price of the bond evolves as $B(t)=\exp \left(\int_{0}^{t} r(s) d s\right) B(0)$, where $r(t) \geq 0$ is a random process and $B(0)$ is given.

It is assumed that $W(\cdot)$ is a standard Wiener process on a given standard probability space $(\Omega, \mathcal{F}, \mathrm{P})$, where $\Omega$ is a set of elementary events, $\mathcal{F}$ is a complete $\sigma$-algebra of events, and $\mathrm{P}$ is a probability measure. Let $\mathcal{F}_{t}$ be a filtration generated by the currently observable data. We assume that the process $(S(t), a(t), \delta(t))$ is $\mathcal{F}_{t}$-adapted and that $\mathcal{F}_{t}$ does not depend on $\left\{W\left(t_{2}\right)-W\left(t_{1}\right)\right\}_{t_{2} \geq t_{1} \geq t}$. In particular, this means that the process $(S(t), a(t), \delta(t))$ is currently observable and $\delta(t)$ does not depend on $\left\{W\left(t_{2}\right)-W\left(t_{1}\right)\right\}_{t_{2} \geq t_{1} \geq t}$. Assume that $\mathcal{F}_{0}$ is the $P$-augmentation of the set $\{\emptyset, \Omega\}$, and that $a(t)$ does not depend on $\left\{W\left(t_{2}\right)-W\left(t_{1}\right)\right\}_{t_{2} \geq t_{1} \geq t}$. For simplicity, $a(t)$ is assumed to be a bounded process.

Consider the case of a European call option with the payoff function $F(S(T), K)=(S(T)-K)^{+}$. Let the strike price $K>0$ be given and let $\sigma(t)=\sigma, \rho(t)=\rho$ be nonrandom. However, the case when $\sigma(t)$ and $\rho(t)$ are random are not excluded. Let the expiry time of the option $T>0$ be fixed. The time-to-maturity $\tau$ is the time interval between spot time $t$ and expiry time $T$ such that $\tau=T-t$. Let $C_{B S}(t, T, S(t), \sigma, \rho, K)$ denote the Black-Scholes price for the European vanilla call option with the payoff function $F(S(T), K)$ described above under the assumption that $(\sigma(s), \rho(s))=(\sigma, \rho)$ $(\forall s>t)$, where $\sigma \in(0,+\infty)$ is non-random. Assuming that the dividend rate is zero, the BlackScholes formula for European vanilla call options is

$$
C_{B S}(t, T, S(t), \sigma, \rho, K)=S(t) \mathscr{N}\left(d_{+}(t, T, S(t), \sigma, \rho, K)\right)-K e^{-\rho(T-t)} \mathscr{N}\left(d_{-}(t, T, S(t), \sigma, \rho, K)\right),
$$


where $\mathscr{N}(x)$ is the cumulative distribution function of the standardized Gaussian distribution, and

$$
\begin{aligned}
& d_{+}(t, T, S(t), \sigma, \rho, K) \triangleq \frac{\log (S(t) / K)+\rho(T-t)}{\sigma \sqrt{T-t}}+\frac{\sigma \sqrt{T-t}}{2}, \\
& d_{-}(t, T, S(t), \sigma, \rho, K) \triangleq d_{+}(t, T, S(t), \sigma, \rho, K)-\sigma \sqrt{T-t} .
\end{aligned}
$$

Let

$$
\sigma(t)^{2} \triangleq \frac{1}{T-t} \int_{t}^{T} \delta(s)^{2} d s, \quad \rho(t) \triangleq \frac{1}{T-t} \int_{t}^{T} r(s) d s .
$$

If $\delta(s)$ and $r(s)$ are random but $\sigma(t)$ and $\rho(t)$ are not random, (2) gives the fair price of a European vanilla call option where the fair price is understood in the sense of risk neutral pricing. We assume that $\rho(t)=\rho$ is constant. In practice, $\sigma(t)$ is often estimated by inverting the Black-Scholes option pricing formula with respect to the price of a European vanilla option contract as a solution of the nonlinear equation

$$
C_{B S}(t, T, S(t), \sigma, \rho, K)=\text { The observed price of option . }
$$

The solution for this equation, the nonrandom value $\sigma_{\text {imp }}(t)$, is said to be the implied volatility.

In the classical Black-Scholes framework, the standard implied volatility definition $\sigma$ gives its value as a function of $\rho, C_{B S}(t, T, S(t), \sigma, \rho, K), K, S(t)$, and $\tau$. The standard definition of the implied volatility ignores the fact that, in reality, the risk-free rate is unknown. Usually, some riskfree rate proxy is used as its forecast because the option price depends on its future (forward) curve. It is commonly accepted to use reference interest rates such as bond-equivalent yield of the U.S Treasury-bill, OIS or Libor as the proxy for the risk-free rate. The choice of risk-free rate proxy will affect the magnitude of the difference between implied and realized volatility as depicted in Figure 1.

We suggested to calculate the pair of two unconditionally implied parameters, $\sigma(t)$ and $\rho(t)$, where $\sigma(t)$ is the unconditionally implied volatility, and $\rho(t)$ is the unconditionally implied value of $r(t)$ which we regard as the implied discount rate. Moreover, we want to take into account all the available observed call option prices with different strike prices and expiry times in this calculation, as described in Section 3. 
Panel A: Implied \& realized volatilities

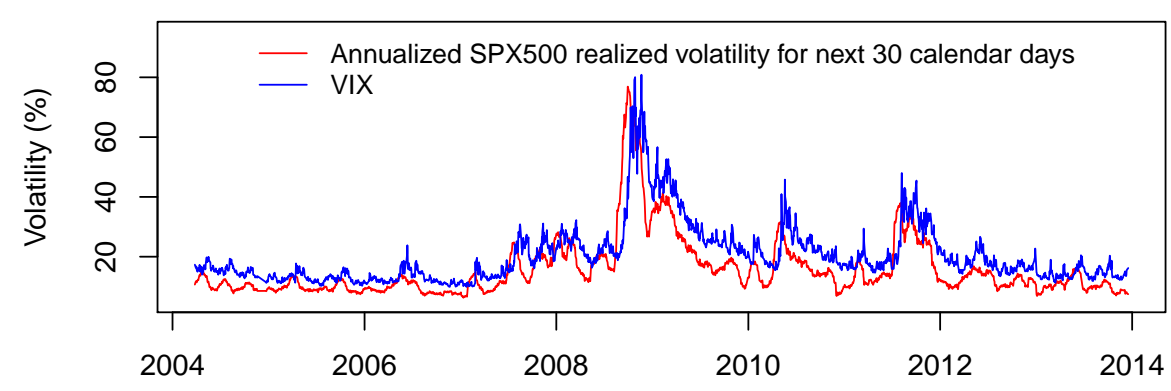

Panel B: Difference between implied and realized volatilities

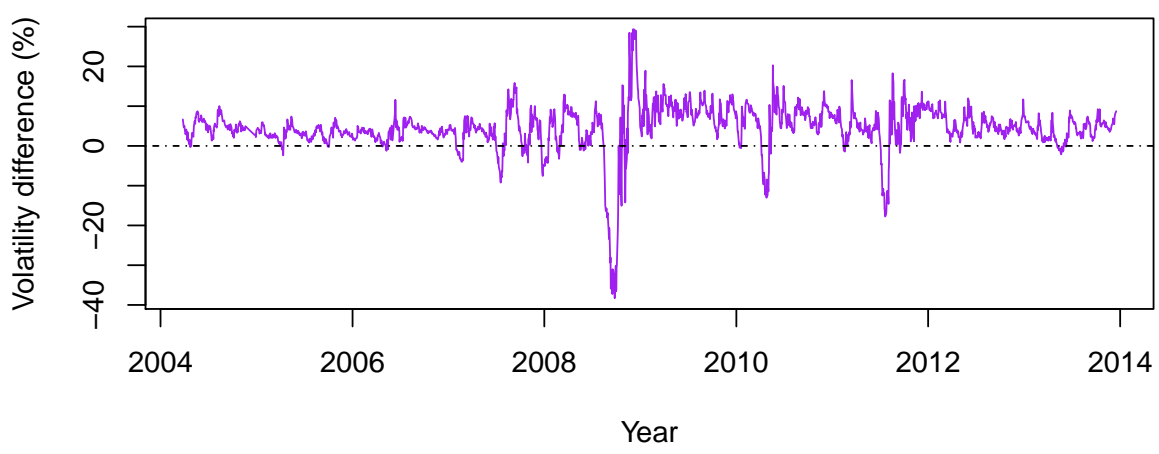

Figure 1: The bond-equivalent yield of the U.S Treasury-bill is used as the risk-free rate proxy in calculating the volatility index (VIX), the annualized expected volatility of the S\&P500 index for the next 30 calendar days. Panel A: Time series plots of VIX and corresponding annualized realized volatility of the S\&P500 index for the next 30 calendar days. Panel B: Time series of the volatility spread between VIX and the corresponding realized volatility. Source: Thomson Reuters Tick History (TRTH) supplied by the Securities Industry Research Centre of Asia-Pacific (SIRCA).

\section{Joint inference of implied parameters using longitudinal op- tions prices}

Let $C\left(t_{i}, T_{j}, K_{j, \ell}\right)$ denote the prices of a set of European vanilla call option contracts that expire at times $T_{j}$ and struck at $K_{j, \ell}$ respectively, for $i=1, \ldots, p, j=1, \ldots, m, \ell=1, \ldots, n_{j}$, where $p, m$, and $n_{j}$, are some given positive integers, $t_{1}<\cdots<t_{p}$. Prices of these option contracts are observed 
at spot times $t_{i}$. Based on the extended Black-Scholes framework defined in Section 2, we regards the implied volatility and implied discount rate as unknown parameters that have to inferred from the observed set of option prices $\left\{C\left(t_{i}, T_{j}, K_{j, \ell}\right)\right\}$.

We accept the following assumptions.

(A) Parameter dependence assumption. We assume that the price of an option contract $C\left(t_{i}, T_{j}, K_{j, \ell}\right)$ contains information about the implied volatility $\sigma_{i m p, j, \ell}\left(t_{i}\right)$ and about the implied discount rate $\rho_{j}\left(t_{i}\right)$ at time $t_{i}$ for the time period, or tenor, of $T_{j}-t_{i}$ The association of $\rho_{j}\left(t_{i}\right)$ with expiry time accommodates the presence of discount rate term structure. The association of $\sigma_{i m p, j, \ell}\left(t_{i}\right)$ with strike and expiry time accommodates the presence of the implied volatility smile across strike prices and the implied volatility term structure across times to maturity, two important features of the implied volatility surface demonstrated by many empirical studies (see, e.g. Rubinstein, 1994; Dupire, 1994; Derman and Kani, 1994; Dumas et al., 1998; Cont, 2001; Cont et al., 2002).

(B) Parameter stability assumption: We consider reasonably short time intervals $\left[t_{1}, t_{p}\right]$, and we assume that there is some stability for the implied volatility and the implied discount rate within these time intervals. More precisely, we assume that

$$
\sigma_{i m p, j, \ell,\left[t_{1}, t_{p}\right]}=\sigma_{i m p, j, \ell}\left(t_{1}\right)=\cdots=\sigma_{i m p, j, \ell}\left(t_{p}\right), \quad \rho_{j,\left[t_{1}, t_{p}\right]}=\rho_{j}\left(t_{1}\right)=\cdots=\rho_{j}\left(t_{p}\right) .
$$

This assumption can be justified as follows. An assumption on the stability in the implied volatility of an option contract over a short time interval is commonly made in the risk management activities in the banking industry. Discrete rebalancing of hedge positions for a portfolio of option contracts, usually performed on a daily basis, implicitly assume that, for practical purpose, the implied volatility remain the same within the time period between two successive rebalancing activities. Additionally, the reference interest rates used as proxy for the risk-free rates are usually updated on a daily basis, except on weekends and holidays. This implies that the risk-free rate, or discount rate, term structure is assumed to remain the same between two successive announcements of this set of reference rates. 
In fact, parameter stability in the framework of non-parametric estimation procedures can be achieved via the use of different smoothing kernels. Our framework corresponds to the regularization with respect to the uniform kernel. Examples of applications of non-uniform kernels such as Nadaraya-Watson kernel, local polynomial kernel and spline kernel for non-parametric modelling of the implied volatility surface can be found in Ben Hamida and Cont (2005), Coleman et al. (2013) and Fengler and Hin (2015), among many others. Their implementation relies on modelling the implied volatility as a tensor-product of kernel basis with respect to times to maturity and strike prices of the options contract assuming that the risk-free rate is known. However, in our present framework both the implied volatility and implied discount rate are unknown parameters. So far, it is unclear how to combine the kernel basis of both parameters, two orthogonal sequences of basis for the implied volatility and one other sequence of kernel basis for the implied discount rate, to ensure achievement of the optimal convergence rate to the observed data in the spirit of Stone $(1982 ; 1994)$. The issue of optimal bandwidth determination for kernel basis and optimal knot placement for B-spline basis pose additional technical challenges. We suggest to leave this important question for future research.

Based on these assumptions, we construct a system of nonlinear equations

$$
\begin{aligned}
& C_{B S}\left(t_{i}, T_{j}, S\left(t_{i}\right), \sigma_{i m p, j, \ell,\left[t_{1}, t_{p}\right]}, \rho_{j,\left[t_{1}, t_{p}\right]}, K_{j, \ell}\right)=C\left(t_{i}, T_{j}, K_{j, \ell}\right), \\
& i=1, \ldots, p, \quad j=1, \ldots, m, \quad \ell=1, \ldots, n_{j},
\end{aligned}
$$

to calculate $\sigma_{i m p, j, \ell,\left[t_{1}, t_{p}\right]}$ and $\rho_{j,\left[t_{1}, t_{p}\right]}$ by mapping the set of observed option prices $C\left(t_{i}, T_{j}, K_{j, \ell}\right)$ to the extended Black-Scholes option pricing formula defined in (2).

If $p=1$, then (4) is underdefined because there are $m+\sum_{j=1}^{m} n_{j}$ unknown variables to be solved for only $\sum_{j=1}^{m} n_{j}$ nonlinear equations present in the system since $m \geq 1$. If $p>1$, then there are $m+\sum_{j=1}^{m} n_{j}$ unknown variables to be solved based on $p \times \sum_{j=1}^{m} n_{j}$ equations. Since $m \leq \sum_{j=1}^{m} n_{j}$, we have $p \times \sum_{j=1}^{m} n_{j}>m+\sum_{j=1}^{m} n_{j}$. Note that $m=\sum_{j=1}^{m} n_{j}$ occurs only in the extreme situation where there is only one option contract for every expiry time in the data set. Assuming a reasonable amount of options data are present in the dataset for analysis, we usually have more than one option contract for each expiry time in the dataset, i.e., $m<\sum_{j=1}^{m} n_{j}$. Therefore, assuming that 
$m<\sum_{j=1}^{m} n_{j}$, the system is overdefined for $p>1$.

Let $\boldsymbol{\sigma}=\left(\sigma_{i m p, 1,1,\left[t_{1}, t_{p}\right]}, \ldots, \sigma_{i m p, m, n_{m},\left[t_{1}, t_{p}\right]}\right), \boldsymbol{\rho}=\left(\rho_{1,\left[t_{1}, t_{p}\right]}, \ldots, \rho_{m,\left[t_{1}, t_{p}\right]}\right), \boldsymbol{\theta}=(\boldsymbol{\sigma}, \boldsymbol{\rho})$, and

$$
\Psi(\boldsymbol{\theta})=\sum_{i=1}^{p} \sum_{j=1}^{m} \sum_{\ell=1}^{n_{j}}\left(C\left(t_{i}, T_{j}, K_{j, \ell}\right)-C_{B S}\left(t_{i}, T_{j}, S\left(t_{i}\right), \sigma_{i m p, j, \ell,\left[t_{1}, t_{p}\right]}, \rho_{j,\left[t_{1}, t_{p}\right]}, K_{j, \ell}\right)\right)^{2} .
$$

We consider only $\sigma_{i m p, j, \ell,\left[t_{1}, t_{p}\right]}>0, \rho_{j,\left[t_{1}, t_{p}\right]}>0, j=1, \ldots, m, \ell=1, \ldots, n_{j}$. Since we cannot expect to find a solution for the overdefined system (4), we replace solution of this system by the solution of the optimization problem $\boldsymbol{\sigma}=\left(\sigma_{\text {imp, } 1,1,\left[t_{1}, t_{p}\right]}, \ldots, \sigma_{\text {imp, }, n_{m},\left[t_{1}, t_{p}\right]}\right)$ and $\boldsymbol{\rho}=\left(\rho_{1,\left[t_{1}, t_{p}\right]}, \ldots, \rho_{m,\left[t_{1}, t_{p}\right]}\right)$ as the following optimization problem:

$$
\text { Minimize } \Psi(\boldsymbol{\theta}) \text { over } \boldsymbol{\theta} \text {. }
$$

In general, solution of (6) does not satisfy (4), however, it represents an approximation to the solution. Since objective function (5) is not convex with respect to $\rho_{j,\left[t_{1}, t_{p}\right]}$ and $\sigma_{i m p, j, \ell,\left[t_{1}, t_{p}\right]}$, we implement the numerical solution of (6) via the Zhang-Sanderson's algorithm (Zhang and Sanderson, 2009), a multi-point stochastic-based direct-search optimization techniques that incorporates self-adaptive control parameters to accelerate convergence.

Up to the end of this section, we discuss the numerical solution of (6). We replicate the exposition style of Zhang and Sanderson (2009). We will consider iteration steps $g=1, \ldots, G$, with $g=0$ as the initialization stage.

Initialization stage $(g=0)$ : Generate a set $\boldsymbol{\theta}_{I, 0}=\left\{\left(\boldsymbol{\theta}_{J, I, 0}\right)_{J=1, \ldots, D}, I=1, \ldots, N_{p}\right\} \subset R^{D}$, where $\boldsymbol{\theta}_{J, I, 0}$ is a random number drawn from the uniform distribution $U\left[\boldsymbol{\theta}_{J}^{\text {Lower }}, \boldsymbol{\theta}_{J}^{\text {Upper }}\right]$, and where $\left[\boldsymbol{\theta}_{J}^{\text {Lower }}, \boldsymbol{\theta}_{J}^{U \text { pper }}\right]$ is a user specified interval within which $\boldsymbol{\theta}_{J}, J=1, \ldots, D$, is assumed to be located.

Iteration stage $(g=1, \ldots, G)$ : After initialization, the algorithm enters an iterative loop indexed by $g=1, \ldots, G$. Each iteration consists of three steps known as mutation, crossover and selection.

Mutation step for iteration stage $g$ : We construct vectors $\mathbf{v}_{I, g}=\left\{v_{J, I, g}\right\}_{J=1}^{D}, I=1, \ldots, N_{p}$, by

$$
\mathbf{v}_{I, g}=\boldsymbol{\theta}_{I, g}+F_{I, g}\left(\boldsymbol{\theta}_{b e s t, g}^{p}-\boldsymbol{\theta}_{I, g}\right), \quad I=1, \ldots, N_{p}
$$


where $\boldsymbol{\theta}_{\text {best,g }}^{p}$ is randomly chosen from the subset of $\left\{\boldsymbol{\theta}_{I, g}, I=1, \ldots, N_{p}\right\}$ such that $\Psi\left(\boldsymbol{\theta}_{\text {best,g }}^{p}\right)$ is located within the lowest $p$ percentiles among the values $\left\{\Psi\left(\boldsymbol{\theta}_{I, g}\right), I=1, \ldots, N_{p}\right\}$, while $F_{I, g}$ is drawn randomly from the Cauchy distribution with location parameter $\mu_{F, g}$ and scale parameter 0.1 , and then to be either truncated to 1 if $F_{I, g} \geq 1$ or regenerated if $F_{I, g} \leq 0$. Let $\mu_{F, 0}=0.5$, let $\mu_{F, g+1}=(1-c) \mu_{F, g}+c \mu_{L, S_{F, g}, g}$, where $c$ is a user specified parameter, $S_{F, g}=\left\{F_{I, g}: \boldsymbol{\theta}_{I, g} \neq \boldsymbol{\theta}_{I, g+1}\right\}$, and $\mu_{L, S_{F, g}, g}=\sum_{F_{I, g} \in S_{F, g}} F_{I, g}^{2} / \sum_{F_{I, g} \in S_{F, g}} F_{I, g}$. Any element $v_{J, I, g}$ that violates the user specified parameter constraint interval $\left[\boldsymbol{\theta}_{J}^{L o w e r}, \boldsymbol{\theta}_{J}^{U \text { pper }}\right]$ will be reset to a value within the interval by the rule

$$
v_{J, I, g}= \begin{cases}\boldsymbol{\theta}_{J}^{\text {Lower }}+\zeta_{J, I, g}\left(\boldsymbol{\theta}_{J}^{\text {Upper }}-\boldsymbol{\theta}_{J}^{\text {Lower }}\right), & \text { if } v_{J, I, g}<\boldsymbol{\theta}_{J}^{\text {Lower }}, \\ \boldsymbol{\theta}_{J}^{U p p e r}-\zeta_{J, I, g}\left(\boldsymbol{\theta}_{J}^{U \text { Upper }}-\boldsymbol{\theta}_{J}^{\text {Lower }}\right), & \text { if } v_{J, I, g}>\boldsymbol{\theta}_{J}^{U p p e r},\end{cases}
$$

where $\zeta_{J, I, g}$ is randomly drawn from uniform distribution $U[0,1]$.

Crossover step for iteration stage g: We construct vectors $\mathbf{u}_{I, g}=\left\{u_{J I, I, g}\right\}_{J=1}^{D}, I=1, \ldots, N_{p}$,

$$
u_{J, I, g}= \begin{cases}v_{J, I, g}, & \text { if } \xi_{J, I, g} \leq C R_{I, g}, \\ \boldsymbol{\theta}_{J, I, g}, & \text { otherwise },\end{cases}
$$

where $\xi_{J, I, g}$ is randomly drawn from uniform distribution $U[0,1]$, while $C R_{I, g}$ is generated by truncating a random draw from a Gaussian distribution $\mathscr{N}\left(\mu_{C R, g}, 0.01\right)$ with respect to a floor of 0 and a ceiling of 1 . Let $\mu_{C R, 0}=0.5$, and let $\mu_{C R, g+1}=(1-c) \mu_{C R, g}+c \mu_{A, C R, g}$, where $c$ is a user specified parameter.

Selection step for iteration stage $g$ : We update $\boldsymbol{\theta}_{I, g+1}(t)$ by the rule

$$
\boldsymbol{\theta}_{I, g+1}= \begin{cases}\mathbf{u}_{I, g}, & \text { if } \Psi\left(\mathbf{u}_{I, g}\right)<\Psi\left(\boldsymbol{\theta}_{I, g}\right), \\ \boldsymbol{\theta}_{I, g}, & \text { otherwise. }\end{cases}
$$

The selection is successful if $\boldsymbol{\theta}_{I, g+1} \neq \boldsymbol{\theta}_{I, g}$.

Algorithm termination: The parameter vector $\boldsymbol{\theta}_{\text {best }, G}$ delivering the minimum of $\Psi\left(\boldsymbol{\theta}_{I, G}\right)$ over $I=$ $1, \ldots, N_{p}$ is the best estimate of the parameters in the set $\left\{\boldsymbol{\theta}_{I, G}, I=1, \ldots, N_{p}\right\}$, and $\boldsymbol{\theta}_{\text {best,G}}$ is regarded as the approximate solution of (4) by minimization of objective function (5) over a given number of iteration steps $G$.

Algorithm parameter settings: In our experiments, we set $G=5,000$. This was sufficient to achieve an acceptable level of precision. We set $c=0.2, p=0.01$ and $N_{p}=50 \times D$ for the 
simulation studies reported in Section 3.1, and set $c=0.15, p=0.01$ and $N_{p}=25 \times D$ for the empirical data analysis reported in Section 3.2.

Uncertainty bound for estimated parameters: The estimated parameters $\boldsymbol{\sigma}_{\text {best,G}}$ and $\boldsymbol{\rho}_{\text {best }, G}$ are approximate solutions to (4). Some measures of goodness-of-fit can give us an idea of the solution accuracy to the system of nonlinear equations. As pointed out by an anonymous referee, the mean squared error, variance and bias squared are criteria used for practical estimation on the trading floor, while the standard error is a measure of choice for statistical and financial econometric inference. However, given the complexity of the problem at hand, bootstrap procedures are too computationally intensive to be implemented. As an alternative to the classical goodness-of-fit measures such as mean squared error and standard error, we propose to perform empirical assessment of the distribution properties of the member vectors at algorithm termination and their corresponding objective function value to quantify the uncertainty bound for $\sigma_{b e s t, G}$ and $\rho_{b e s t, G}$ to give an idea of the goodness-of-fit.

At algorithm termination, the population consists of a set of $D$-dimensional member vectors $\left\{\boldsymbol{\theta}_{I, G}, I=\right.$ $\left.1, \ldots, N_{p}\right\}$. They represent the iterative stochastic perturbation of the initialization vectors $\left\{\boldsymbol{\theta}_{I, 0}, I=\right.$ $\left.1, \ldots, N_{p}\right\}$ via the Zhang-Sanderson's algorithm. Therefore, one may view $\left\{\boldsymbol{\theta}_{I, G}, I=1, \ldots, N_{p}\right\}$ as a set of random variables. Each member vector $\boldsymbol{\theta}_{I, G}, I=1, \ldots, N_{p}$, is associated with its corresponding value of objective function such that $\boldsymbol{\theta}_{I, G} \rightarrow \Psi\left(\boldsymbol{\theta}_{I, G}\right), I=1, \ldots, N_{p}$. If $G$ is sufficiently large such that the set of member vectors converge, one hopes, to the global minimum, then $\min \left\{\Psi\left(\boldsymbol{\theta}_{I, G}\right), I=1, \ldots, N_{p}\right\}$ should be small in absolute terms. Additionally, the dispersion of $\left\{\Psi\left(\boldsymbol{\theta}_{I, G}\right), I=1, \ldots, N_{p}\right\}$ can be described empirically by studying the range and percentiles of the distribution of $\left\{\Psi\left(\boldsymbol{\theta}_{I, G}\right), I=1, \ldots, N_{p}\right\}$. The narrower the interval

$$
\left[\Psi_{\text {Lower }}\left(\boldsymbol{\theta}_{I, G}\right), \Psi_{U p p e r}\left(\boldsymbol{\theta}_{I, G}\right)\right] \stackrel{\Delta}{=}\left[\min \left\{\Psi\left(\boldsymbol{\theta}_{I, G}\right), I=1, \ldots, N_{p}\right\}, \max \left\{\Psi\left(\boldsymbol{\theta}_{I, G}\right), I=1, \ldots, N_{p}\right\}\right],
$$

the more likely that the member vectors are converging towards the minimum. The percentiles of $\left\{\Psi\left(\boldsymbol{\theta}_{I, G}\right), I=1, \ldots, N_{p}\right\}$ will give additional information on the shape of its distribution.

While we regard $\boldsymbol{\theta}_{\text {best }, G}=\left(\boldsymbol{\sigma}_{\text {best }, G}, \boldsymbol{\rho}_{\text {best }, G}\right)$ as the set of parameters that represent the approximate solutions to (4), $\boldsymbol{\theta}_{\text {best }, G}$ may be also be regarded as a $D$-dimensional random variables. For a sufficiently 
large $G$ such that $\min \left\{\Psi\left(\boldsymbol{\theta}_{I, G}\right), I=1, \ldots, N_{p}\right\}$ is small and the interval $\left[\Psi_{L o w e r}\left(\boldsymbol{\theta}_{I, G}\right), \Psi_{U p p e r}\left(\boldsymbol{\theta}_{I, G}\right)\right]$ is narrow, we may view the set $\left\{\sigma_{I, G: i m p, j, \ell\left[t_{1}, t_{p}\right]}, I=1, \ldots, N_{p}\right\}$ as the set of random possible solutions of $\sigma_{i m p, j, \ell,\left[t_{1}, t_{p}\right]}$, where $j=1, \ldots, m, \ell=1, \ldots, n_{j}$, and the set $\left\{\rho_{I, G: j,\left[t_{1}, t_{p}\right]}, I=1, \ldots, N_{p}\right\}$ as the set of random possible solutions of $\rho_{j,\left[t_{1}, t_{p}\right]}$, where $j=1, \ldots, m$. We suggest to quantify the parameter uncertainty of $\sigma_{\text {best, },: i m p, 1,1,\left[t_{1}, t_{p}\right]}$ as an estimator of $\sigma_{i m p, j, \ell,\left[t_{1}, t_{p}\right]}$ by the interval $\left[\sigma_{\text {Lower:imp, }, \dot{\ell},\left[t_{1}, t_{p}\right]}, \sigma_{U p p e r: i m p, j, \ell,\left[t_{1}, t_{p}\right]}\right] \triangleq\left[\min \left\{\sigma_{I, G: i m p, j, \ell,\left[t_{1}, t_{p}\right]}, I=1, \ldots, N_{p}\right\}, \max \left\{\sigma_{I, G: i m p, j, \ell,\left[t_{1}, t_{p}\right]}, I=1, \ldots, N_{p}\right\}\right]$,

where $j=1, \ldots, m, \ell=1, \ldots, n_{j}$, and to quantify the parameter uncertainty of $\rho_{b e s, G:\left\{:\left[t_{1}, t_{p}\right]\right.}$ as an estimator of $\rho_{j,\left[t_{1}, t_{p}\right]}$ by the interval

$$
\left[\rho_{\text {Lower } ; . j\left[t_{1}, t_{p}\right]}, \rho_{U p p e r ; j ;\left[t_{1}, t_{p}\right]}\right] \triangleq\left[\min \left\{\rho_{I, G: j,\left[t_{1}, t_{p}\right]}, I=1, \ldots, N_{p}\right\}, \max \left\{\rho_{I, G: j,\left[t_{1}, t_{p}\right]}, I=1, \ldots, N_{p}\right\}\right]
$$

where $j=1, \ldots, m$.

Our approach in quantifying parameter estimation uncertainty is inspired by the work of Ben Hamida and Cont (2005) who suggested the probabilistic approach to the model calibration problem within the stochastic-based differential evolution optimization framework. The evolving population converges, after a sufficiently large number of iteration steps, to the set of global minima of a pricing error which may or may not be reduced to a single element, leading to a family of pricing model parameters compatible with market prices that can then be used to quantify model parameter uncertainty. This approach relies neither on large sample results nor on the assumption of independently and identically distributed errors across options.

The Zhang-Sanderson algorithm belongs to the family of stochastic-based differential evolution optimization framework considered in Ben Hamida and Cont (2005). Our current work of inferring parameters from market prices is similar in spirit to the notion of model calibration as defined in Ben Hamida and Cont (2005). It appears that their interpretation of the member vectors as a family of pricing model parameters compatible with market prices is applicable in our case. Casting the Ben Hamida-Cont notion of model parameter uncertainty in our framework, the family of possible values of $\sigma_{i m p, j, \ell\left[t_{1}, t_{p}\right]}$ based on the set of population vectors at algorithm 
termination is $\left\{\sigma_{I, G: i m p, j, \ell,\left[t_{1}, t_{p}\right]}, I=1, \ldots, N_{p}\right\}$, where $j=1, \ldots, m, \ell=1, \ldots, n_{j}$, while the family of possible values of $\rho_{j,\left[t_{1}, t_{p}\right]}$ is $\left\{\rho_{I, G: j,\left[t_{1}, t_{p}\right]}, I=1, \ldots, N_{p}\right\}$, where $j=1, \ldots, m$. This allow us to describe, in our framework, the global goodness-of-fit uncertainty of the solution for the entire system of nonlinear equations using the interval $\left[\Psi_{\text {Lower }}\left(\boldsymbol{\theta}_{I, G}\right), \Psi_{U p p e r}\left(\boldsymbol{\theta}_{I, G}\right)\right]$, and to describe the model

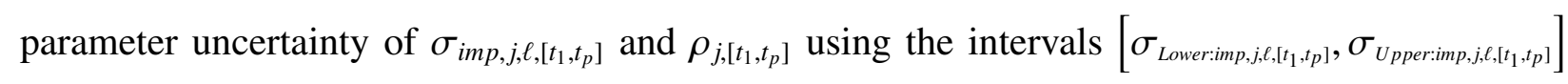
and $\left[\rho_{\text {Lower: }:\left[t_{1}, t_{p}\right]}, \rho_{U p p e r: j,\left[t_{1}, t_{p}\right]}\right]$ respectively.

Computation acceleration by parallel implementation: We deployed 48 parallel cores on the National eResearch Collaboration Tools and Resources (NeCTAR) eResearch cloud infrastructure to carry out all the calculations reported in this paper. We used the parallel implementation of the Zhang-Sanderson algorithm in the form of DEoptim (Ardia et al., 2012) package for the R computing environment ( $\mathrm{R}$ Core Team, 2012). The two numerical experiments described in Section 3.1 took 5.68 and 5.74 hours respectively to complete on a single core, but took 1.23 and 1.24 hours respectively instead on 48 parallel cores, demonstrating an approximate $78 \%$ reduction in computation time. If (4) consists of only about 10 nonlinear equations, it is still feasible to solve them on a standard personal computer within a reasonable time frame. For our purpose, we need to deal with systems with 100 or more nonlinear equations. In this situation, the computation workload need to be distributed across many concurrent processors so that they can be solve within a reasonable time frame for practical use at the trading desk.

Choice of objective function: We have performed the parameter estimation based on synthetic test datasets and historical option prices using two different objective functions. In the first setting, we used (5). In the second setting, we used the penalized $L_{2}$-loss function $\Psi(\boldsymbol{\theta})+\lambda\|\boldsymbol{\theta}\|^{2}$, where $\lambda$ is the regularization parameter determined using the $L$-curve approach (Hansen, 2000) as outlined in Smith and Bowers (1993), and $\|\boldsymbol{\theta}\|^{2}=\sum_{j=1}^{m} \sum_{\ell=1}^{n_{j}} \sigma_{i m p, j, \ell,\left[t_{1}, t_{p}\right]}^{2}+\sum_{j=1}^{m} \rho_{j,\left[t_{1}, t_{p}\right]}^{2}$ is the ridge penalty constructed in line with Bouchouev and Isakov (1999) and Egger and Engl (2005). It appears that the implied discount rates and implied volatilities estimated using these two objective functions are similar. Therefore, the numerical performance using objective function $\Psi(\boldsymbol{\theta})+\lambda\|\boldsymbol{\theta}\|^{2}$ is not reported herein. The similarity between these two sets of results implies that problem (4) constructed using this set of data is well posed. 


\subsection{Numerical experiment with test data}

We assess the performance of the proposed algorithm in terms of its convergence profile, parameter estimation accuracy, and computation time based on two synthetic test data sets.

Test data sets construction: We construct two sets of test data, each simulate prices of a set of European vanilla call option contracts observed on two instances, one day apart. The synthetic prices in both test data sets are simulated from the same set of hypothetical times to maturity, spot and strike prices, and implied volatilities using (2) assuming that the dividend rate is zero. They differ only in the hypothetical discount rate scenario; one data set simulate an up-sloping discount rate term structure, the other simulate an inverted term structure instead. For the set of test data that simulate the up-sloping term structure, the hypothetical discount rates corresponding to the unique times to maturity at each instance sorted in increasing order of magnitude are $0.002,0.004$, $0.006,0.012,0.015$ and 0.019 respectively. For the set of test data that simulate the inverted term structure, the hypothetical discount rates corresponding to the unique times to maturity at each instance sorted in increasing order of magnitude are $0.002,0.004,0.019,0.015,0.012$, and 0.006 respectively.

For each of the two test data sets, we specify the hypothetical times to maturity, expressed in years, for the synthetic option contracts observed at the first instance to be $0.17,0.42,0.69,0.94,1$, and 1.5 while for those observed at the second instance to be $0.17-d, 0.42-d, 0.69-d, 0.94-d, 1-$ $d$, and $1.5-d$, where $d=1 / 365$. For each synthetic option contract, we set the hypothetical spot price, implied volatility and discount rate to be the same at both instances. We set the spot rate to be $\$ 590$, and the strike to spot ratio to be $0.85,0.9,0.95,1,1.05,1.1,1.15,1.2,1.3$, and 1.4. The implied volatilities used in the simulation of the test data sets are adapted from the implied volatilities of the European call options on the S\&P500 equity index quoted in October 1995 and reported in Table 1 of Andersen and Brotherton-Ratcliffe (1997). They are chosen to provide a volatility surface with smile that constitute a system of nonlinear equations that is numerically challenging to solve. 


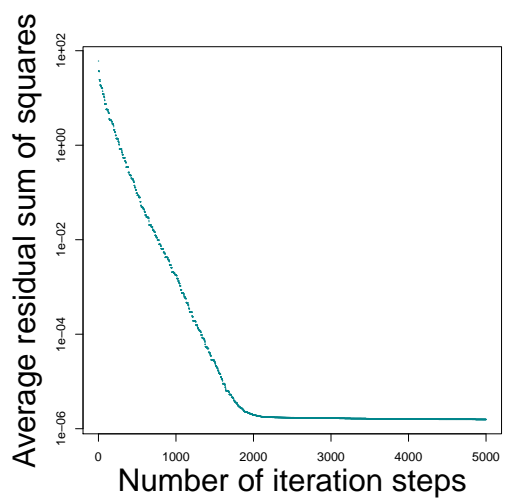

Figure 2: Convergence profile in estimation of implied volatilities and discount rates from the test data sets synthesized using the up-sloping discount rate term structure.

Each data set consists of 120 synthetic data points; the first 60 simulate the prices of 60 option contracts observed at one instance in time while the remaining 60 simulate the prices of the same 60 option contracts observed one day later. Based on (4), we construct a system of 120 nonlinear equations with 66 unknown parameters, i.e., 60 implied volatilities and 6 implied discount rates, where $p=2, m=6, n_{j}=10$, and $t_{2}-t_{1}=1 / 365$ year. This system of equation is overdefined and uniqueness of solution exists.

Convergence profile: For both up-sloping and inverted discount rate scenarios, the average residual sum of squares, defined as $\Psi\left(\boldsymbol{\theta}_{\text {best }, G}\right) / 3300$, decrease to the order of $1 \times 10^{-6}$ in approximately 2,000 iterations. Since the convergence profiles for both scenarios are similar, only that for the up-sloping term structure is depicted in Figure 2.

Error profile: Let $\sigma_{\text {imp }, j, \ell,\left[t_{1}, t_{2}\right]}^{\text {TRUE,Test data }}, j=1, \ldots, 6, \ell=1, \ldots, 10$, be the set of true implied volatilities and $\rho_{j,\left[t_{1}, t_{2}\right]}^{T R U E, T e s t}$ data $, j=1, \ldots, 6$, be the set of true discount rates used to generate the set of simulated call prices in the test data sets. Furthermore, let

$$
\operatorname{Error}\left(\sigma_{\text {imp }, j, \ell,\left[t_{1}, t_{2}\right]}^{\text {Test data }}\right)=\left|\sigma_{\text {best, }, \text { :imp }, j,\left[,\left[t_{1}, t_{2}\right]\right.}^{\text {Test }}-\sigma_{\text {imp }, j, \ell,\left[t_{1}, t_{2}\right]}^{\text {TRUE,Tata }}\right|
$$

be the solution error of $\sigma_{\text {imp }, j, \ell,\left[t_{1}, t_{2}\right]}^{T R U E, T e s t a}$ and let

$$
\operatorname{Error}\left(\rho_{j,\left[t_{1}, t_{2}\right]}^{\text {Test data }}\right)=\left|\rho_{\text {best } \left., \mathrm{G}: j, I_{1}, t_{p}\right]}^{T \text { Test data }}-\rho_{j,\left[t_{1}, t_{2}\right]}^{T R \text { Test data }}\right|
$$




\begin{tabular}{|c|c|c|c|c|c|c|c|c|c|c|}
\hline \multirow{2}{*}{$\begin{array}{l}\text { Time to maturity } \\
\text { at first instance } \\
\text { (years) }\end{array}$} & \multicolumn{10}{|c|}{ Strike/Spot } \\
\hline & 0.85 & 0.9 & 0.95 & 1 & 1.05 & 1.1 & 1.15 & 1.2 & 1.3 & 1.4 \\
\hline & \multicolumn{10}{|c|}{$\operatorname{Error}\left(\sigma_{\text {imp, }, j,\left[,\left[t_{1}, t_{2}\right]\right.}^{\text {Test dat }}\right) \times 10^{-3}:$ Up-sloping discount rate term structure } \\
\hline 0.17 & 42.36 & 9.41 & 3.88 & 1.51 & 0.73 & 0.44 & 0.37 & 0.23 & 2.50 & 102.67 \\
\hline 0.42 & 57.37 & 24.35 & 12.79 & 7.38 & 4.57 & 3.11 & 2.31 & 2.10 & 1.85 & 1.86 \\
\hline 0.69 & 40.22 & 23.10 & 14.67 & 9.86 & 6.87 & 4.87 & 3.72 & 3.09 & 2.44 & 2.16 \\
\hline 0.94 & 21.53 & 14.51 & 10.17 & 7.42 & 5.54 & 4.16 & 3.24 & 2.65 & 1.94 & 1.61 \\
\hline 1.00 & 23.10 & 15.75 & 11.10 & 8.19 & 6.16 & 4.67 & 3.64 & 2.96 & 2.14 & 1.90 \\
\hline \multirow[t]{2}{*}{1.50} & 8.69 & 6.59 & 5.12 & 4.04 & 3.23 & 2.61 & 2.15 & 1.79 & 1.34 & 1.04 \\
\hline & \multicolumn{10}{|c|}{ Error $\left(\sigma_{\text {imp }, j, \ell,\left[t_{1}, t_{2}\right]}^{\text {Test data }}\right) \times 10^{-3}$ : Inverted discount rate term structure } \\
\hline 0.17 & 42.63 & 9.42 & 3.89 & 1.51 & 0.74 & 0.44 & 0.49 & 0.12 & 2.74 & 36.11 \\
\hline 0.42 & 52.93 & 23.33 & 12.31 & 7.11 & 4.41 & 3.01 & 2.24 & 2.00 & 1.53 & 1.64 \\
\hline 0.69 & 15.56 & 9.85 & 6.44 & 4.36 & 3.05 & 2.15 & 1.64 & 1.34 & 1.08 & 1.02 \\
\hline 0.94 & 23.96 & 15.98 & 11.13 & 8.10 & 6.03 & 4.52 & 3.51 & 2.87 & 2.10 & 1.80 \\
\hline 1.00 & 31.99 & 21.35 & 14.96 & 11.03 & 8.30 & 6.31 & 4.94 & 4.04 & 2.99 & 2.59 \\
\hline 1.50 & 20.92 & 15.54 & 11.93 & 9.37 & 7.48 & 6.04 & 4.99 & 4.16 & 3.11 & 2.45 \\
\hline
\end{tabular}

Table 1: Error profiles for the implied volatilities estimated from the test data sets for the synthetic option contracts with different combinations of times to maturity and strike prices. The upper and lower panels depict results for up-sloping and inverted discount rate term structures respectively.

be the solution error of $\rho_{j,\left[t_{1}, t_{2}\right]}^{T R U E, T e s t}$ data respectively.

The error profiles for the implied volatilities calculated based on the two test data sets are displayed in Table 1. For both test data sets, the solution error for implied volatilities are in general small in the order of $10^{-1}$ to $10^{-4}$ across all strikes and times to maturity. In general, the error is less for synthetic contracts simulating out of the money (OTM) options compared to those into the money (ITM). This is likely because the values of OTM options are smaller, facilitating the numerical algorithm to perform optimizing search in the parameter space. However, the error profile for far OTM and near expiry scenario, such as that displayed in Table 1 for moneyness of 1.4 and time to maturity of 0.17 year, appear to be larger than contracts that out of but near to the money.

The error profiles for numerical solutions of the implied discount rates are displayed in Table 2. For both implied discount rate scenarios, the error profile for implied discount rates is in general small in the order of $10^{-3}$.

Parameter estimation uncertainty: The summary statistics for the set of objective function values $\left\{\Psi\left(\boldsymbol{\theta}_{I, G}\right), I=1, \ldots, 3300, G=5000\right\}$ that correspond to the 3,300 member vectors at algorithm 


\begin{tabular}{ccc}
\hline Time to maturity at & \multicolumn{2}{c}{ Error $\left(\rho_{j,\left[t_{1}, t_{2}\right]}^{\text {Test data }}\right) \times 10^{-3}$} \\
\cline { 2 - 3 } first spot time (years) & Up-sloping discount rate term structure & Inverted discount rate term structure \\
\hline 0.17 & 2.94 & 2.95 \\
0.42 & 9.05 & 8.73 \\
0.69 & 9.35 & 3.94 \\
0.94 & 5.90 & 6.31 \\
1.0 & 6.19 & 8.71 \\
1.5 & 2.44 & 5.87 \\
\hline
\end{tabular}

Table 2: Error profiles for the implied discount rates estimated from the test data sets simulating up-sloping or inverted discount rate term structure for the synthetic option contracts with different times to maturity.

termination are displayed in Table 3. The interval $\left[\Psi_{\text {Lower }}\left(\boldsymbol{\theta}_{I, G}\right), \Psi_{U p p e r}\left(\boldsymbol{\theta}_{I, G}\right)\right]$ is narrow for both test data sets, $\left[1.882 \times 10^{-4}, 1.977 \times 10^{-4}\right]$ for the data set that simulate up-sloping discount rate scenario, and $\left[1.959 \times 10^{-4}, 2.051 \times 10^{-4}\right]$ for the data set that simulate inverted discount rate scenario. This implies that the 3,300 member vectors that represent potential solutions to (4) based on the test datasets at algorithm termination produce similar overall goodness-of-fit to the systems. Since we used (5) as the objective function, $\left\{\Psi\left(\theta_{I, G}\right), I=1, \ldots, 3300, G=5000\right\}$ represents the set of residual sum of squares goodness-of-fit measure between the simulated option prices and the corresponding Black-Scholes model prices calculated using each member vector in the population as potential solutions to (4). For both test data sets, the residual sum of squares for the solution vectors are small, implying good overall fit with respect to the simulated option prices.

\begin{tabular}{|c|c|c|c|c|c|c|c|c|c|}
\hline \multirow{2}{*}{$\begin{array}{l}\text { Discount rate scenario } \\
\text { Percentiles }\end{array}$} & \multicolumn{9}{|c|}{ Percentile values of $\left\{\Psi\left(\boldsymbol{\theta}_{I, G}\right), I=1, \ldots, 3300, G=5000\right\}\left(\times 10^{-4}\right)$} \\
\hline & Min & 1 st & 10th & 25 th & 50th (Median) & 75 th & 90th & 99th & Max \\
\hline Up-sloping & 1.882 & 1.898 & 1.916 & 1.925 & 1.935 & 1.944 & 1.952 & 1.964 & 1.977 \\
\hline Inverted & 1.959 & 1.975 & 1.992 & 2.002 & 2.013 & 2.022 & 2.030 & 2.042 & 2.051 \\
\hline
\end{tabular}

Table 3: The percentiles of the objective function values calculation based on test data from the entire set of population vectors.

Table 4 tabulates $\left[\sigma_{\text {Lower:imp, }, j, \ell,\left[t_{1}, t_{2}\right]}^{\text {Teet dat }}, \sigma_{U p p e r \text { rimp }, j, \ell,\left[t_{1}, t_{2}\right]}^{\text {Test }}\right]$, the parameter uncertainty bounds for $\sigma_{\text {imp, dat, },\left[t_{1}, t_{2}\right]}^{\text {Test }}, j=$ $1,6, \ell=1, \ldots, 10$. The error bounds for all estimated values of $\sigma_{i m p, j, \ell,\left[t_{1}, t_{2}\right]}^{\text {Test data }}$ are narrow. The values of implied volatilities for any of the synthetic option contracts estimated using different member vectors in the population may differ by a magnitude of, at most, approximately 0.01 .

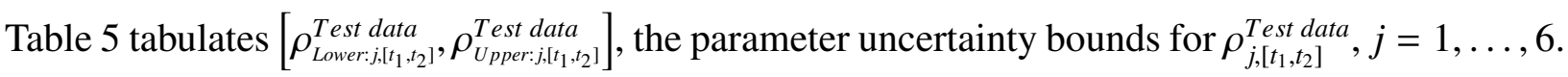




\begin{tabular}{|c|c|c|c|c|c|c|c|c|c|}
\hline \multirow[b]{2}{*}{ Maturity (years) } & \multirow[b]{2}{*}{ Strike/Spot } & \multicolumn{4}{|c|}{ Up-sloping discount rate scenario } & \multicolumn{4}{|c|}{ Inverted discount rate scenario } \\
\hline & & $\sigma_{\text {best }, \text { G:imp }, j, \ell,\left[t_{1}, t_{2}\right]}$ & Min & Median & Max & $\sigma_{\text {best }, \text { G:imp }, j, \ell,\left[t_{1}, t_{2}\right]}$ & Min & Median & Max \\
\hline 0.17 & 0.85 & 0.148 & 0.137 & 0.142 & 0.150 & 0.146 & 0.136 & 0.141 & 0.152 \\
\hline 0.17 & 0.90 & 0.159 & 0.158 & 0.158 & 0.159 & 0.158 & 0.158 & 0.158 & 0.159 \\
\hline 0.17 & 1 & 0.111 & 0.111 & 0.111 & 0.112 & 0.111 & 0.111 & 0.111 & 0.112 \\
\hline 0.17 & 1.05 & 0.101 & 0.101 & 0.101 & 0.101 & 0.101 & 0.101 & 0.101 & 0.101 \\
\hline 0.17 & 1.10 & 0.097 & 0.096 & 0.097 & 0.097 & 0.097 & 0.096 & 0.097 & 0.097 \\
\hline 0.17 & 1.20 & 0.142 & 0.141 & 0.142 & 0.142 & 0.142 & 0.141 & 0.142 & 0.142 \\
\hline 0.17 & 1.30 & 0.167 & 0.163 & 0.169 & 0.173 & 0.169 & 0.163 & 0.168 & 0.172 \\
\hline 0.17 & 1.40 & 0.097 & 0.073 & 0.131 & 0.161 & 0.146 & 0.122 & 0.150 & 0.172 \\
\hline 1.50 & 0.85 & 0.160 & 0.160 & 0.160 & 0.160 & 0.138 & 0.138 & 0.138 & 0.138 \\
\hline 1.50 & 0.90 & 0.153 & 0.153 & 0.153 & 0.153 & 0.137 & 0.137 & 0.137 & 0.137 \\
\hline 1.50 & 0.95 & 0.146 & 0.146 & 0.146 & 0.146 & 0.134 & 0.134 & 0.134 & 0.134 \\
\hline 1.50 & 1.20 & 0.111 & 0.111 & 0.111 & 0.111 & 0.107 & 0.107 & 0.107 & 0.107 \\
\hline 1.50 & 1.30 & 0.106 & 0.106 & 0.106 & 0.106 & 0.102 & 0.102 & 0.102 & 0.102 \\
\hline 1.50 & 1.40 & 0.101 & 0.101 & 0.101 & 0.101 & 0.098 & 0.098 & 0.098 & 0.098 \\
\hline
\end{tabular}

Table 4: Summary statistics for implied volatility estimation uncertainty based on two test data sets.

The error bounds for all estimated values of $\rho_{j,\left[t_{1}, t_{2}\right]}^{T e s t \text { data }}$ are narrow. The values of inferred discount rate for any of the synthetic option contracts estimated using different member vectors in the population may differ by a magnitude of, at most, approximately 0.0004 .

\begin{tabular}{|c|c|c|c|c|c|c|c|c|}
\hline \multirow[b]{2}{*}{ Maturity (years) } & \multicolumn{4}{|c|}{ Up-sloping discount rate scenario } & \multicolumn{4}{|c|}{ Inverted discount rate scenario } \\
\hline & $\rho_{\text {best }, G: j,\left[t_{1}, t_{2}\right], \text { Test data }}$ & Min & Median & $\operatorname{Max}$ & $\rho_{\text {best }, G: j,\left[t_{1}, t_{2}\right], \text { Test data }}$ & Min & Median & $\operatorname{Max}$ \\
\hline 0.17 & 0.0049 & 0.0049 & 0.0051 & 0.0052 & 0.0050 & 0.0048 & 0.0051 & 0.0052 \\
\hline 0.42 & 0.0130 & 0.0130 & 0.0130 & 0.0131 & 0.0129 & 0.0129 & 0.0129 & 0.0129 \\
\hline 0.69 & 0.0153 & 0.0153 & 0.0154 & 0.0154 & 0.0236 & 0.0236 & 0.0237 & 0.0237 \\
\hline 0.94 & 0.0179 & 0.0179 & 0.0179 & 0.0179 & 0.0222 & 0.0222 & 0.0222 & 0.0222 \\
\hline 1 & 0.0212 & 0.0212 & 0.0212 & 0.0212 & 0.0196 & 0.0196 & 0.0196 & 0.0196 \\
\hline 1.50 & 0.0214 & 0.0214 & 0.0214 & 0.0214 & 0.0148 & 0.0148 & 0.0148 & 0.0148 \\
\hline
\end{tabular}

Table 5: Summary statistics for implied discount rate estimation uncertainty based on two test data sets.

\subsection{Numerical illustration with historical S\&P500 call options data}

Data description: The historical day-close prices of S\&P500 index European call option contracts traded at the Chicago Board of Options Exchange (CBOE) are used for the empirical analysis reported in this section. They were obtained from Market Data Express LLC. We use OTM options 
with moneyness between 1.0 and 1.2 because they contain more information on implied volatility than ITM option. OTM options not "too far" out of the money are suitable for implied volatility and risk-free rate analysis because far OTM options are low in liquidity and are associated with higher numerical uncertainty on implied volatility (Cont and da Fonseca, 2002).

Option contracts with remaining time to maturity between 60 and 320 days are considered in our analysis. Short expiry options are excluded from this study as the information content of these options in terms of volatility is questionable, as demonstrated by Ben Hamida and Cont (2005) using empirical options data.

We compare the implied discount rates inferred from the options data with contemporaneously quoted Libor and OIS rates. The USD Libor term structure is a set of uncollateralized interbank reference rate for various tenors while the USD OIS rates are OTC-quoted interest rate swap rates the floating legs of which are based on discrete daily compounded Effective Federal Fund Rate. While the OIS rates is virtually credit risk free, the Libor rates are designed to reflect the average credit risk among different banks. Historical data of the Libor term structure was downloaded from the Economic Research Division, Federal Reserve Bank of St. Louis while the historical data of the Libor-OIS spread rates, the difference between the Libor reference rates and the OTC-quoted US Dollar OIS rates, was retrieved from the Thomson Reuters Tick History (TRTH) supplied by the Securities Industry Research Centre of Asia-Pacific (SIRCA). Subtracting the Libor-OIS spread rates from the Libor reference rates for the same tenor recovers the corresponding OIS rates. The Libor and OIS rates were then converted from the discrete interest rates convention to continuously compound convention for use.

Both the Libor reference rates and Libor-OIS spread rates are quoted at 11 am London time while the day-close option prices are observed at $3.15 \mathrm{pm}$ Chicago time, a few hours behind the London time. In view of the time lag between the publication of the former two interest rate term structures and the availability of the option price data from which the implied discount rates are estimated, the implied discount rates cannot be expected to match the Libor and OIS rates exactly due to arrival of new information during this lag time period. 


\subsubsection{The impact of risk-free rate proxy on implied volatility and volatility spread}

We constructed four systems of overdefined nonlinear equations using (4) based on option prices observed on May 18th \& 19th 2010, May 18th \& 19th 2011, May 23rd \& 24th 2012, and May 22nd \& 23rd 2013 respectively, and estimated the implied discount rates and implied volatilities by minimization of (5) using the Zhang-Sanderson algorithm.

For comparison, we display in Table 7 and the upper row of Figure 4 the implied discount rates and the contemporaneously quoted Libor and OIS rates. The tenor corresponding to the implied discount rates differ from sample to sample and do not match exactly the fixed tenor of the contemporaneously quoted Libor and OIS term structures. Therefore, the Libor and OIS rates corresponding to the tenor of the inferred discount rate term structures had to be interpolated to facilitate comparison.

From these four samples of option prices, we select subsets of option chain in each sample that have similar moneyness for comparison of the implied volatilities. Option chains with strike prices USD1,150, USD1,400, USD1,370, and USD1,725 were selected from the samples of options data observed on May 18th \& 19th 2010, May 18th \& 19th 2011, May 23rd \& 24th 2012, and May 22nd \& 23rd 2013 respectively for this purpose. They were use to construct Table 8 and the lower row of Figure 4.

In order to compare, from the same sets of option prices, the implied volatilities estimated using the implied discount rates as the risk-free rate proxy with the implied volatilities estimated using the interpolated contemporaneously quoted Libor or OIS rates as the risk-free rate proxy, we display these estimated implied volatilities in Table 8. We use the implied discount rates and the tenor matching interpolated values of the contemporaneously quoted Libor and OIS rates reported in Table 7 to estimate the implied volatilities from the same sets of option prices and report them in Table 8 .

The uncertainty bound of the estimated implied volatility and implied discount rate, defined in (8) and (9) respectively, are inferred from these four samples and depicted in Table 9. 


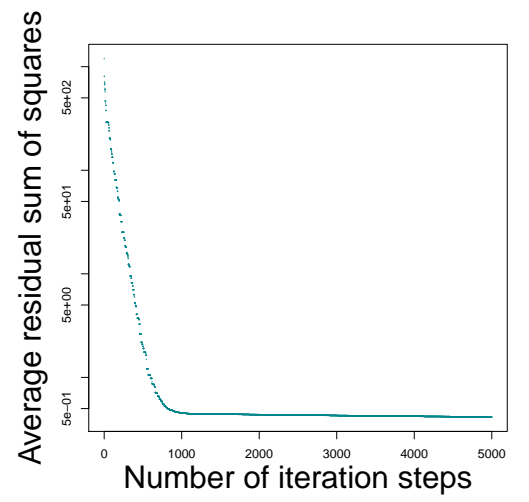

Panel A: May 18th \& 19th 2010

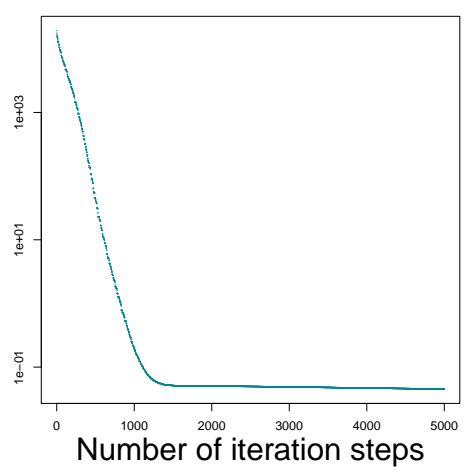

Panel B: May 22th \& 23rd 2013

Figure 3: Convegence profiles for calculating the optimal approximate solutions to two systems of nonlinear equations formulated using samples of option prices observed on different pairs of consecutive trading dates:

Convergence profile: The convergence profiles for all four samples are similar. In Figure 3 we depicts two of them. After approximately 2,000 iterations, the average residual sum of squares reached a value smaller than one. This magnitude of average residual sum of squares corresponds to a pricing discrepancy between observed and model prices of the option that is approximately the size of the bid-ask spread. This is an acceptable level of precision because, in reality, the observed option price jumps between the bid and ask prices, and attempt to achieve higher precision than the bid-ask spread is of no practical significance (Ben Hamida and Cont, 2005). As displayed in Table 6, the goodness-of-fit uncertainty interval $\left[\Psi_{L o w e r}\left(\boldsymbol{\theta}_{I, G}\right), \Psi_{U p p e r}\left(\boldsymbol{\theta}_{I, G}\right)\right]$ for each of these four samples is narrow, implying that the member vectors at algorithm termination produce similar overall goodness-of-fit to the systems of equations.

\begin{tabular}{|c|c|c|c|c|c|c|c|c|c|c|}
\hline \multirow[b]{2}{*}{ Percentiles } & \multirow[t]{2}{*}{$N_{p}$} & \multicolumn{8}{|c|}{ Percentile values of $\left\{\Psi\left(\boldsymbol{\theta}_{I, G}\right), I=1, \ldots, N_{p}\right\}\left(\times 10^{-4}\right)$} & \multirow[b]{2}{*}{ Max } \\
\hline & & Min & 1 st & 10th & 25 th & 50th (Median) & 75th & 90th & 99th & \\
\hline I & 166 & 50.666 & 50.766 & 50.843 & 50.884 & 50.933 & 50.983 & 51.022 & 51.086 & 51.172 \\
\hline II & 174 & 10.165 & 10.169 & 10.172 & 10.174 & 10.175 & 10.177 & 10.179 & 10.182 & 10.184 \\
\hline III & 250 & 147.037 & 147.042 & 147.048 & 147.050 & 147.053 & 147.056 & 147.059 & 147.062 & 147.067 \\
\hline IV & 262 & 11.834 & 11.864 & 11.888 & 11.901 & 11.916 & 11.930 & 11.942 & 11.960 & 11.981 \\
\hline
\end{tabular}

Table 6: Summary statistics for objective function values calculation based on each of the four samples, indexed by I, II, III \& IV respectively, from the entire set of population vectors. I: May 18th \& 19th 2010. II: May 18th \& 19th 2011, III: May 23rd \& 24th 2012. IV: May 22nd \& 23rd 2013. 
Implied discount rate and risk-free rate proxy: The Libor and OIS rates quoted on both trading dates in these four samples of option prices are found to be similar, with a day-to-day fluctuation of about 0.0001 . We show in Table 7 the tenor matching interpolated values of Libor and OIS rates from contemporaneously quote term structures for one of these samples. While we display, in Table 7, descriptive statistics to illustrate how different the implied discount rates are from the standard risk-free rate proxies, we did not perform correlation measures and Mincer-Zarnowitz regression to study the relationship between implied discount rates and standard risk-free rate proxies. This is because the numbers of implied discount rates data we have estimated are too small to construct an arbitrage-free discount curve using interpolation methods such as those proposed by Ramponi (2002), Marangio et al. (2002), Laurini and Moura (2010), and Fengler and Hin (2014) among others. In order to perform these formal econometric analysis, either the standard risk-free rate proxies or the implied discount rates need to interpolated to construct a set of interpolated Libor, OIS and implied discount rates corresponding to a set of common times to maturity for this purpose. Numerical error and loss of information incurred by such interpolation may compromise the econometric analysis performed based on these interpolated data.

\begin{tabular}{|c|c|c|c|c|c|c|c|c|}
\hline \multirow[b]{2}{*}{ Times to maturity (year) } & \multicolumn{4}{|c|}{ May 22nd 2013} & \multicolumn{4}{|c|}{ May 23rd 2013} \\
\hline & 0.6110 & 0.6603 & 0.8329 & 0.8575 & 0.6082 & 0.6575 & 0.8301 & 0.8548 \\
\hline Implied discount rate & 0.0189 & 0.0184 & 0.0157 & 0.0133 & 0.0189 & 0.0184 & 0.0157 & 0.0133 \\
\hline Libor & 0.0048 & 0.0051 & 0.0059 & 0.0060 & 0.0048 & 0.0050 & 0.0059 & 0.0060 \\
\hline OIS rate & 0.0012 & 0.0012 & 0.0013 & 0.0013 & 0.0014 & 0.0014 & 0.0014 & 0.0014 \\
\hline
\end{tabular}

Table 7: The implied discount rates are estimated based on S\&P500 call options prices recorded on May 22nd \& 23rd 2013 versus tenor matching interpolated values of Libor and OIS rates.

Not all market participants are accessible to liquidity at the same cost. Depending on their credit rating, default probability inferred from their corporate bond and their single- named credit default swap rate if available, and other factors, their funding cost may be higher than the Libor rate. As pointed out by an anonymous referee, the difference between the implied discount rate and standard risk-free rate proxy to some extent reflect the premium paid by agents to fund their investment.

In Table 7, we depict the differences between implied discount rates estimated based on option prices quoted on May 22nd 2013, and the Libor and OIS rates interpolated from the corresponding 

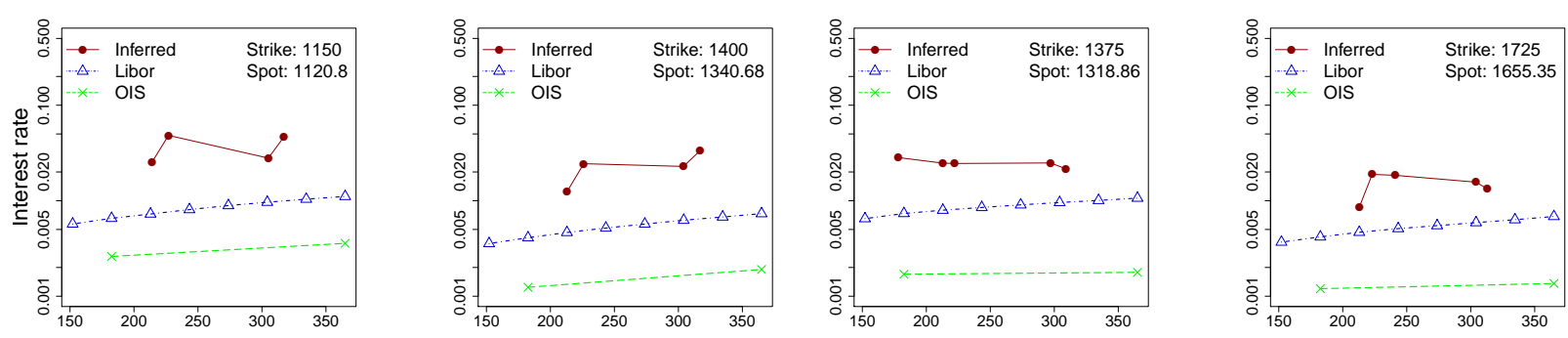

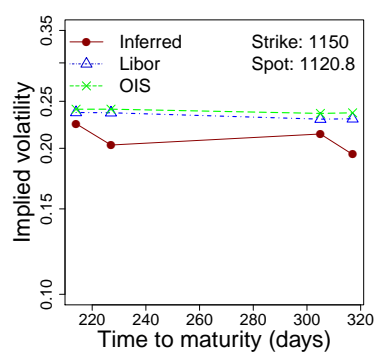

May 18th 2010

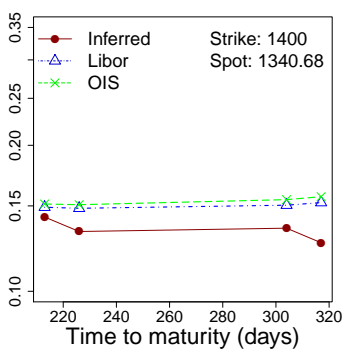

May 18th 2011

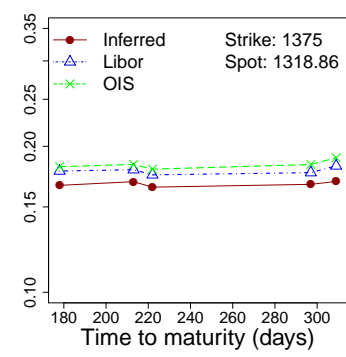

May 23th 2012

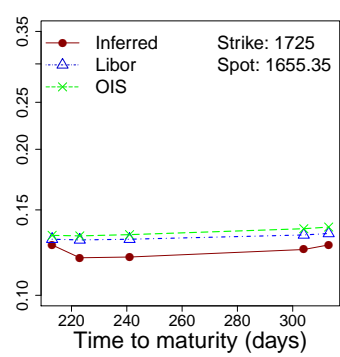

May 22th 2013

Figure 4: Upper row: Term structures of implied discount rates and contemporaneously quoted Libor and OIS rates. Lower row: Term structures of implied volatility estimated based on implied discount rates, and contemporaneously quoted Libor and OIS rates.

contemporaneously quoted term structures. Larger differences exist for results estimated based on option prices quoted on other dates. For example, the differences between implied discount rates estimated based on option prices quoted on May 19th 2011 and the interpolated contemporaneous Libor and OIS rates can be as large as 0.03 depending on the time to expiry of the option contracts.

These differences appear to be larger at the longer end of the tenor. There are some empirical evidence (see, e.g., Gefang et al., 2011) suggesting that the higher the bank credit risk premium, the higher the discount rate at the longer end of the tenor. In Figure 4 and Table 7, we see that the implied discount rates at the longer end of the tenor are higher than the contemporaneously quoted Libor and OIS rates. This may imply that the credit risk for some market participants were higher than the average bank credit risk.

Credit default swap (CDS) spread is a direct measure of the credit risk. The differences between the implied discount rates and interpolated OIS rates as shown in Table 7 are comparable to the 
CDS spreads of US firms with an average Moody's and S\&P ratings that range between BBB and BB, as illustrated in Table II of Longstaff et al. (2005) and Table 1 of Wang et al. (2013).

Implied volatility: Since the implied discount rates in these samples are higher than the contemporaneously quoted Libor and OIS rates, the implied volatilities calculated by inverting the BlackScholes option pricing formula using the implied discount rate as the risk-free rate proxy are lower than those calculated using either Libor or OIS rates as the risk-free rate proxy. We depict, in Figure 4 and Table 8, the implied volatilities calculated based on one of these samples for illustration.

The estimation of implied volatility, performed using the risk-neutral measure, depends on the choice of risk-free rate proxy. In contrast, the estimation of realized volatility, performed using the physical measure, does not depend on the risk-free rate. The fact that the choice of risk-free rate proxy affects the former but not the latter implies that, given an estimated realized volatility, the difference between the implied and the realized volatilities may be affected by the choice of risk-free rate proxy.

In the extant literature studying the information content of implied volatility and its role as a predictor of the realized volatility, the choices of risk-free rate proxy used in the empirical work are varied; for example, Canina and Figlewski (1993) used the average of the Eurodollar deposit rate and the broker call rate on each date as the risk-free rate proxy, Christensen and Prabhala (1998) used one month LIBOR rate, Jiang and Tian (2005) used daily Treasury bill yields, while Busch et al. (2011) used the US Eurodollar deposit one-month middle rate quote instead. It is possible that the market participants' aggregate choice of risk-free rate proxy may differ from the choices of risk-free rate proxy commonly reported in the literature. If we do not choose the market participants' aggregate choice of risk-free rate proxy, we will not be able to recover, from the option prices, the market participants' aggregate expectation of the underlying asset return volatility for the remaining life span of the option contracts. The implied volatility estimated based on standard choices of risk-free rate proxy may be a biased estimation of the market participants' aggregate expectation of the underlying asset return volatility. 
Econometric approaches such as univariate and encompassing regression used by Canina and Figlewski (1993), Christensen and Prabhala (1998), and Jiang and Tian (2005), as well as the in-sample Mincer and Zarnowitz (1969) forecasting regressions used by Busch et al. (2011) are powerful tools for investigating the information content of the implied volatilities. However, if we regress the realized volatilities against the implied volatility estimated based on the standard choices of risk-free rate proxy, it will lead to error in the estimation of the implied volatility information content quantified by the $R$-squared values of these regression analyses. This is because the implied volatilities estimated this way are different from the market participants' aggregate expectation of the underlying asset return volatility. If the chosen risk-free rate proxy is higher than the market participants' aggregate choice of risk-free rate proxy, the corresponding implied volatility underestimates the market participants' aggregate expectation of the underlying asset return volatility, and underestimates the risk premium, and vice versa.

In the present work, we confined our study to OTM European vanilla call options based on their favourable error profile demonstrated in Table 1. In order to investigate the information content of implied volatility estimated using the implied discount rate in the spirit of Canina and Figlewski (1993), Christensen and Prabhala (1998), Jiang and Tian (2005), and Busch et al. (2011), among others, it would be necessary to first generalize our proposed framework to improve the estimation error profile for ITM options. This is vital because implied volatilities for both ITM and OTM European vanilla call options need to be estimated with comparable accuracy to facilitate accurate interpolation of the at the money implied volatility to be used in the aforementioned regression analyses on grounds that at the money implied volatility has the highest correlation with the realized volatility (Jiang and Tian, 2005). We suggest to leave this important aspect for future research.

\subsubsection{Time series of implied discount rates using options data from 2004 to 2013}

In Section 3.2.1, we found, based on four samples of options data between 2010 to 2013, that the implied discount rates appear to be higher than the contemporaneously quoted Libor and OIS rates. In order to investigate whether this finding applies to a longer time frame, we estimate the time 


\begin{tabular}{|c|c|c|c|c|c|c|c|c|}
\hline \multirow{2}{*}{$\begin{array}{l}\text { Option chain strike price: } \mathbf{1 7 2 5} \\
\text { Times to maturity (year) }\end{array}$} & \multicolumn{4}{|c|}{ May 22nd 2013} & \multicolumn{4}{|c|}{ May 23rd 2013} \\
\hline & 0.6110 & 0.6603 & 0.8329 & 0.8575 & 0.6082 & 0.6575 & 0.8301 & 0.8548 \\
\hline (i) Proxy: Implied discount rate & 0.1195 & 0.1199 & 0.1243 & 0.1270 & 0.1195 & 0.1199 & 0.1243 & 0.1270 \\
\hline (ii) Proxy: Libor & 0.1301 & 0.1305 & 0.1332 & 0.1341 & 0.1294 & 0.1298 & 0.1327 & 0.1331 \\
\hline (iii) Proxy: OIS rate & 0.1326 & 0.1334 & 0.1372 & 0.1383 & 0.1318 & 0.1324 & 0.1365 & 0.1371 \\
\hline
\end{tabular}

Table 8: Implied volatilities calculated using implied discount rates, contemporaneously quoted Libor or OIS rates as the risk-free rate proxy based on S\&P500 call option prices recorded on May 22nd \& 23rd 2013.

\begin{tabular}{|c|c|c|c|c|c|c|c|c|}
\hline \multirow{2}{*}{$\begin{array}{l}\text { Option chain strike price: } \mathbf{1 7 2 5} \\
\text { Times to maturity (year) }\end{array}$} & \multicolumn{4}{|c|}{ Implied volatility } & \multicolumn{4}{|c|}{ Implied discount rate } \\
\hline & 0.6110 & 0.6603 & 0.8329 & 0.8575 & 0.6082 & 0.6575 & 0.8301 & 0.8548 \\
\hline Lower error bound & 0.1195 & 0.1199 & 0.1243 & 0.1270 & 0.0188 & 0.0184 & 0.0156 & 0.0133 \\
\hline Best estimate & 0.1195 & 0.1199 & 0.1243 & 0.1270 & 0.0189 & 0.0184 & 0.0157 & 0.0133 \\
\hline Upper error bound & 0.1195 & 0.1200 & 0.1243 & 0.1270 & 0.0189 & 0.0185 & 0.0157 & 0.0134 \\
\hline
\end{tabular}

Table 9: Estimation uncertainty bounds for the implied volatilities and implied discount rates estimated jointly from S\&P500 call options prices recorded on May 22nd \& 23rd 2013.

series of implied discount rates using samples of historical options data between 2004 and 2013, and compare them with the contemporaneously quoted Libor rates.

Time series of implied discount rates: We constructed 10 systems of nonlinear equations using (4) based on different samples of the option prices observed between 2004 and 2013 inclusive. Each sample consists of option prices observed on two consecutive trading days in the same week. These 10 samples are taken approximately one year apart on consecutive trading dates as depicted in Figures 5 and 6.

From these samples, we inferred the implied discount rates and implied volatilities jointly using (6) and compared the implied discount rates with the contemporaneously quoted Libor term. We also investigated whether the implied discount rates are numerically stable with respect to day-to-day variation of the option prices used to construct the nonlinear equations. For each aforementioned sample of option prices, we obtained an additional sample of option prices from another two consecutive trading days that are one day further down the time line and constructed another system 

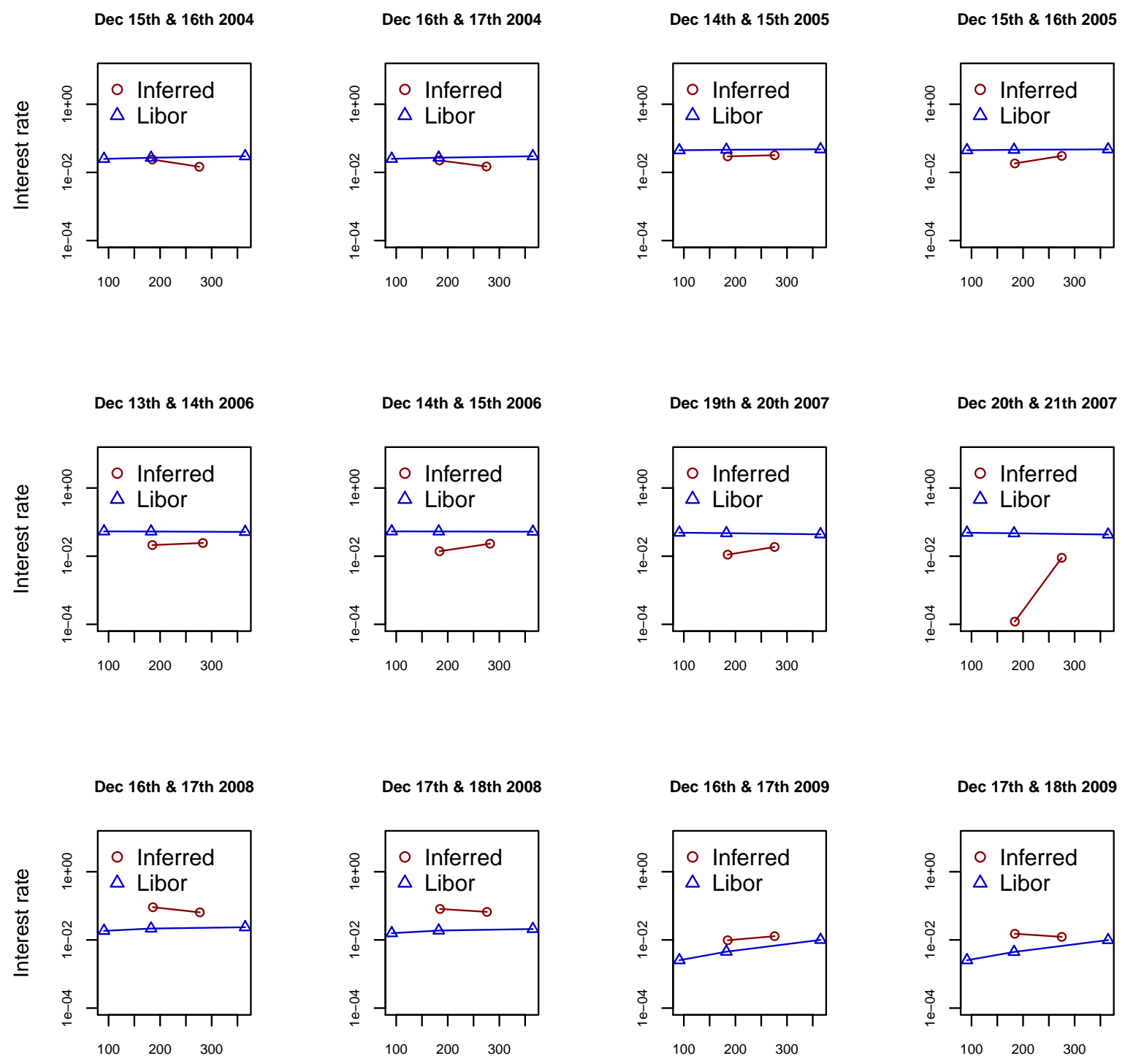

Time to maturity (days)

Time to maturity (days)
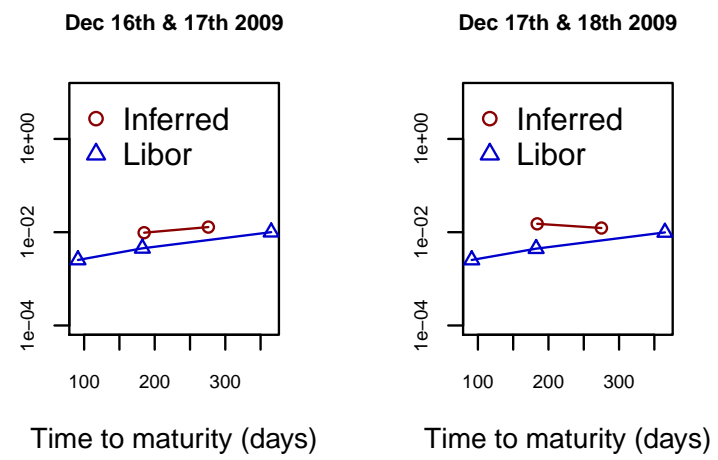

Figure 5: Term structures of implied discount rates inferred from S\&P500 options data from 2004 to 2009. The top of each chart shows the dates of the options data in each sample. Inferred: Implied discount rate. Libor: Contemporaneously quoted Libor rate. 

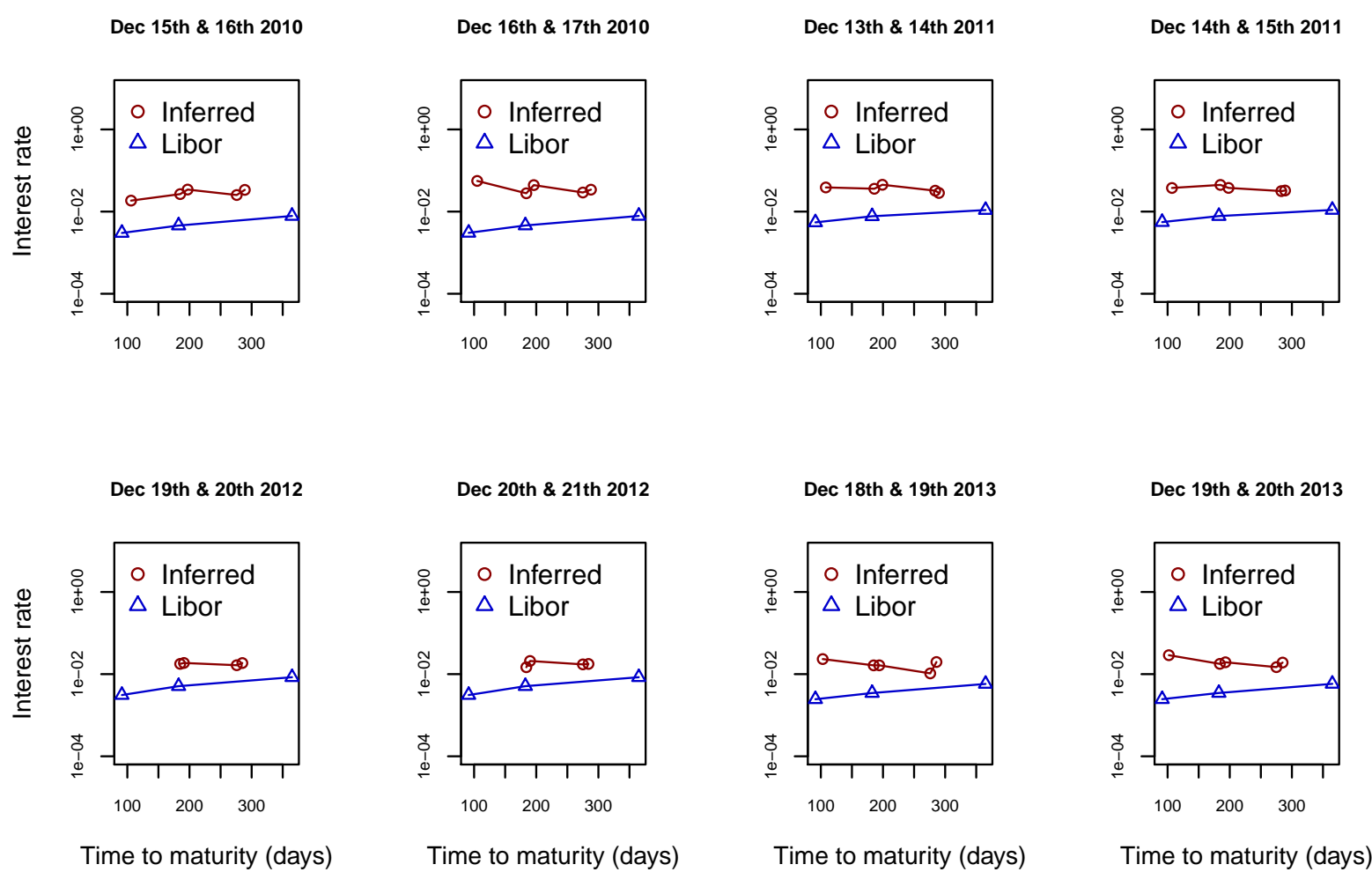

Figure 6: Term structures of implied discount rates inferred from S\&P500 options data from 2010 to 2013. The top of each chart shows the dates of the options data in each sample. Inferred: Implied discount rate. Libor: Contemporaneously quoted Libor rate.

of nonlinear equations from which we inferred the implied discount rates and implied volatilities. These 10 additional systems of nonlinear equations are constructed using option prices observed on pairs of consecutive trading days shown in Figures 5 and 6.

For option prices sampled between 2004 and 2007 inclusive, the implied discount rates appeared to be slightly lower than the contemporaneously quoted Libor term structure. In contrast, for option prices sampled between 2008 and 2013 inclusive, the implied discount rates appeared to be higher than the contemporaneously quoted Libor term structure. The implied discount rates are, in general, numerically stable with respect to day-to-day variation across each pair of samples considered. One possible explanation for the implied discount rate being higher than the contemporaneously quoted Libor rates after the 2007 credit crunch is that the funding costs of the market 
participants have since become more sensitive towards their individual credit risk resulting in the higher risk premium incurred.

For the option prices sampled between 2004 and 2007 inclusive, the Black-Scholes implied volatilities calculated using the the implied discount rates are lower than those calculated using Libor as the risk-free rate proxy, leading to a widening of volatility spread. However, for the options data sampled between 2008 and 2013 inclusive, the Black-Scholes implied volatilities calculated using the implied discount rates are higher than those calculated using Libor as the risk-free rate proxy, leading to a narrowing of volatility spread.

\section{Discussion}

In this paper, we proposed an approach to simultaneously estimate the implied volatilities and implied discount rates from a set of options prices as approximate solutions to a system of overdefined nonlinear equations in order to extract information on the market participants' aggregate choice of risk-free rates proxy and the Black-Scholes model-based implied volatilities for the remaining life span of the options. Due to the computationally intensive nature of solving this system of nonlinear equations, we implemented the numerical solution of this system as an optimization problem on a high-performance computing framework.

Using four sets historical options data sampled a year apart from 2010 to 2013, we found that the implied discount rates inferred from option prices are higher than OIS and Libor rates, two commonly used risk-rate proxy, and that the corresponding Black-Scholes implied volatilities are lower when the implied discount rates are used as risk-free rate proxy. Assuming that the realized volatility is accurately estimated, the volatility spread between the implied volatility and the realized volatility will become narrower for these samples.

We demonstrated that the implied discount rates inferred from option prices sampled from 2004 to 2007 appeared to be slightly lower than the contemporaneously quoted Libor rates. In contrast, the implied discount rates inferred from option prices sampled from 2008 to 2013 appeared to 
be slightly higher than the contemporaneously quoted Libor rates. We also demonstrated that the implied discount rates are in general numerically stable with respect to day-to-day variation.

The proposed approach of inferring implied discount rates and Black-Scholes model-based implied volatilities jointly may be applied to revalue the volatility indexes based on either the S\&P100 index (VXO) or the S\&P500 index (VIX) using the implied discount rates as risk-free rate proxy. In doing so, we can investigate whether the forecasting ability of the revised VXO and VIX may be improved by a change in the choice of risk-free rate proxy. We leave this for future research.

\section{References}

Adams, A. and Booth, B. (1995). Sensitivity measures for equity investment, IMA Journal of Mathematics Applied in Business $\mathcal{E}$ Industry 6: 365-374.

Aït-Sahalia, Y. and Duarte, J. (2003). Nonparametric option pricing under shape restrictions, Journal of Econometrics 116: 9-47.

Aït-Sahalia, Y. and Lo, A. (1998). Nonparametric estimation of state-price densities implicit in financial asset prices, Journal of Finance 53: 499-548.

Aït-Sahalia, Y., Mykland, P. and Zhang, L. (2003). How Often to Sample a Continuous-Time Process in the Presence of Market Microstructure Noise, Review of Financial Studies 18: 351416.

Andersen, L. B. G. and Brotherton-Ratcliffe, R. (1997). The equity option volatility smile: An implicit finite-difference approach, Journal of Computational Finance 1(2): 5-37.

Ardia, D., Mullen, K., Peterson, B. and Ulrich, J. (2012). DEoptim: Differential Evolution in 'R'. version 2.2-2.

Bakshi, G. and Madan, D. (2006). A theory of volatility spreads, Management science 52: 19451956. 
Bank of International Settlement (2013). Towards better reference rate practices: a central bank perspective. A report by a Working Group established by the BIS Economic Consultative Committee (ECC) and chaired by Hiroshi Nakaso, Assistant Governor, Bank of Japan. Available at http://www.bis.org/publ/othp19.pdf.

Ben Hamida, S. and Cont, R. (2005). Recovering volatility from option prices by evolutionary optimization, Journal of Computational Finance 8(4): 1-34.

Black, F. and Scholes, M. (1973). The pricing of options and corporate liabilities, Journal of Political Economy 81(3): 637-654.

Bollerslev, T., Gibson, M. and Zhou, H. (2011). Dynamic estimation of volatility risk premia and investor risk aversion from option-implied and realized volatilities, Journal of Econometrics 160: $235-245$.

Bouchouev, I. and Isakov, V. (1999). Uniqueness, stability and numerical methods for the inverse problem that arise in financial markets, Inverse Problems 15: R95-R116.

Britten-Jones, M. and Neuberger, A. J. (2000). Option prices, implied price processes, and stochastic volatility, Journal of Finance 55(2): 839-866.

Busch, T., Christensen, B. and Nielsen, M, O. (2011). The role of implied volatility in forecasting future realized volatility and jumps in foreign exchange, stock and bond markets, Journal of Econometrics 160: 48-57.

Butler, J. and Schachter, B. (1996). The statistical Properties of Parameters Inferred from the Black-Scholes Formula, International Review of Financial Analysis 3: 223-235.

Canina, L. and Figlewski, S. (1993). The information content of implied volatility, Review of Financial Studies 6: 659-681.

Carr, P. and Wu, L. (2009). Variance risk premiums, Review of Financial Studies 22(3): 13111341. 
Christensen, B. and Prabhala, N. (1998). The relation between implied and realized volatility, Journal of Financial Economics 50: 125-150.

Christoffersen, P., Heston, S. and Jacobs, K. (2006). Option valuation with conditional skewness, Journal of Econometrics 131: 253-284.

Coleman, T., Li, Y. and Cheng, W. (2013). Stable local volatility function calibration using spline kernel, Computational Optimization and Applications 55: 675-702.

Cont, R. (2001). Empirical properties of asset returns: stylized facts and statistical issues, Quantitative Finance 1: 223-236.

Cont, R. and da Fonseca, J. (2002). The dynamics of implied volatility surfaces, Quantitative Finance 2(1): 45-60.

Cont, R., da Fonseca, J. and Durrleman, V. (2002). Stochastic models of implied volatility surfaces, Economic Notes 31(2): 361-377.

Corrado, C. and Miller, T. (2005). The forecast quality of CBOE implied volatility indexes, The Journal of Futures Markets 25: 339-373.

Derman, E. and Kani, I. (1994). Riding on a smile, RISK 7(2): 32-39.

Dokuchaev, N. (2006). Two unconditionally implied parameters and volatility smiles and skews, Applied Financial Economics Letters 2: 199-204.

Dumas, B., Fleming, J. and Whaley, R. E. (1998). Implied volatility functions: Empirical tests, Journal of Finance 53(6): 2059-2106.

Dupire, B. (1994). Pricing with a smile, RISK 7(1): 18-20.

Egger, H. and Engl, H. (2005). Tikhonov regularization applied to the inverse problem of option pricing: convergence analysis and rates, Inverse Problems 21: 1027-1045. 
Fengler, M. R. and Hin, L.-Y. (2014). A simple and general approach to fitting the discount curve under no-arbitrage constraints. Working paper. Available at SSRN: http://ssrn.com/abstract=2478719.

Fengler, M. R. and Hin, L.-Y. (2015). Semi-nonparametric estimation of the call price surface under strike and time-to-expiry no-arbitrage constraints, Journal of Econometrics 184(2): 242261.

Gefang, D., Koop, G. and Potter, S. (2011). Understanding liquidity and credit risks in the financial crisis, Journal of Empirical Finance 18: 903-914.

Hansen, P. C. (2000). The L-Curve and its Use in the Numerical Treatment of Inverse Problems, in Computational Inverse Problems in Electrocardiology, Ed. P. Johnston, Advances in Computational Bioengineering, WIT Press, pp. 119-142.

Jiang, G. J. and Tian, Y. S. (2005). The Model-Free Implied Volatility and Its Information Content, The Review of Financial Studies 18(4): 1305-1342.

Laurini, M. and Moura, M. (2010). Constrained smoothing B-splines for the term structure of interest rates, Insurance: Mathematics and Economics 46: 339-350.

Leibowitz, M., Sorensen, E., Arnott, R. and Hanson, H. (1989). A total differential approach to equity duration, Financial Analysts Journal 45(5): 30-37.

Longstaff, F., Mithal, S. and Neis, E. (2005). Corporate Yield Spreads: Default Risk or Liquidity? New Evidence from the Credit Default Swap Market, The Journal of Finance 60(5): 2213-2253.

Marangio, L., Bernaschi, M. and Ramponi, A. (2002). A review of techniques for the estimation of the term structure, International Journal of Theoretical and Applied Finance 5: 189-221.

Mincer, J. and Zarnowitz, V. (1969). The evaluation of economic forecasts, in J. Mincer (ed.), Economic Forecasts and Expectations, NBER, New York, pp. 3-46.

Palandri, A. (2014). Risk-free rate effects on conditional variances and conditional correlations of stock returns, Journal of Empirical Finance 25: 95-111. 
R Core Team (2012). R: A Language and Environment for Statistical Computing, R Foundation for Statistical Computing, Vienna, Austria. ISBN 3-900051-07-0.

URL: $h t t p: / / w w w . R-p r o j e c t . o r g /$

Ramponi, A. (2002). Adaptive and monotone spline estimation of the cross-sectional term structure, International Journal of Theoretical and Applied Finance 6: 195-212.

Rubinstein, M. (1994). Implied binomial trees, Journal of Finance 49(3): 771-818.

Smith, R. and Bowers, K. (1993). Sinc-Galerkin estimation of diffusivity in parabolic problems, Inverse Problems 9: 113-135.

Stone, C. J. (1982). Optimal global rates of convergence for nonparametric regression, Annals of Statistics 10(4): 1040-1053.

Stone, C. J. (1994). The use of polynomial splines and their tensor products in multivariate function estimation, Annals of Statistics 22(1): 118-184.

Wang, H., Zhou, H. and Zhou, Y. (2013). Credit default swap spreads and variance risk premia, Journal of Banking $\mathcal{F}$ Finance 37: 3733-3746.

Zhang, J. and Sanderson, A. (2009). JADE: Adaptive Differential Evolution with Optional External Archive, IEEE Transactions on Evolutionary Computation 13(5): 945-958. 